\title{
A configuração da organização e sua relação com o planejamento estratégico formal e emergente
}

\author{
Organization's configuration and its relationship with formal and emergent strategic \\ planning
}

\author{
Sergio Bulgacov ${ }^{1}$ \\ Pedro Josemar Pereira dos Santos ${ }^{2}$ \\ Márcia Ramos May ${ }^{3}$
}

\begin{abstract}
Resumo
O propósito deste artigo é compreender as relações entre a configuração organizacional e as práticas de planejamento estratégico. A pesquisa, qualitativa com característica exploratória, aborda comparativamente dois estudos de caso de empresas que têm obtido sucesso acima da média em relação a seus concorrentes. Os procedimentos metodológicos se apoiam na análise de conteúdo em profundidade de entrevistas, observação e dados secundários. A triangulação dos dados sugere que ambas as empresas apresentam práticas de planejamento fortemente relacionadas às características contrastantes dos elementos da configuração organizacional. Características de planejamento emergente são identificadas na rede de lojas de material de construção (MC). Características de planejamento formal são identificadas na empresa de tecnologia (ET). Como base para estudos futuros, a pesquisa sugere que a configuração organizacional condiciona o processo de planejamento de modo recursivo.
\end{abstract}

Palavras-chave: Planejamento estratégico. Configuração organizacional. Planejamento emergente. Planejamento formal.

\begin{abstract}
The aim of this paper is to understand the relationships between organizational configuration and the strategic planning practices. The research, qualitative with an exploratory nature, approaches in a comparative manner two case studies of companies which achieved success above average when compared to their competitors. The methodological procedures are based on in-depth content analysis of interviews, observation, and secondary data. Data triangulation suggests that both companies present planning practices strongly related to the contrasting characteristics of the organizational configuration elements. Emergent planning characteristics are identified in the building material stores network (MC). Formal planning characteristics are identified in the technology company (HT). As a basis for further studies, the research suggests that organizational configuration conditions the planning process in a recursive manner.
\end{abstract}

Keywords: Strategic planning. Organizational configuration. Emergent planning. Formal planning.

Artigo submetido em 26 de abril de 2012 e aceito para publicação em 07 de novembro de 2012.

1 Professor Adjunto da EAESP-FGV. Endereço: Rua Itapeva, 474 -11ำ andar, CEP 01332-000, São Paulo - SP, Brasil. E-mail: s.bulgacov@gmail.com

2 Mestre em Administração da UFPR. Endereço: Av. Pref. Lothario Meissner, 632 - 2º andar - Jardim Botânico, CEP 80210-170, Curitiba-PR, Brasil. E-mail: pjosemar@uol.com.br

3 Professora do Programa de Pós-Graduação em Administração da UFPR. Endereço: Av. Pref. Lothario Meissner, $632-2^{\circ}{ }^{\circ}$ andar Jardim Botânico, CEP 80210-170, Curitiba-PR, Brasil. E-mail: marciarmay@gmail.com 


\section{Introdução}

A principal questão em análise neste artigo se refere à relação entre a configuração das práticas organizacionais e as práticas do planejamento estratégico. Nesse sentido, observa-se clara lacuna da literatura na descrição das práticas configuradas em eventos organizacionais rotineiros. Essa constatação se dá tanto em termos das condições internas próprias como em relação às práticas de planejamento estratégico, que buscam relacionar temporalmente a organização com o seu ambiente.

Tendo em vista o propósito de envolver questões de uma relativa complexidade, optou-se pelo estudo de caso de duas empresas com abordagem qualitativa e referencial interpretativo de análise. As empresas foram selecionadas por ser de setores diferentes, do mesmo porte em termos de número de funcionários, um longo período de atuação no mercado e rápido crescimento e sucesso empresarial ambos acima da média do mercado.

Nesta pesquisa, entende-se configuração organizacional como os elementos, na forma de rotinas organizacionais mais relevantes, que emergiram durante a primeira fase da coleta de dados, sendo eles a origem da empresa, o conteúdo estratégico em termos de produtos e mercados, a estrutura de negócios, o perfil dos gestores, a forma de gestão e o processo estratégico.

Na primeira fase da pesquisa também se destacam, nas empresas pesquisadas, o planejamento estratégico como um dos fatores integrativos desses elementos, as formas de definição da estratégia, as práticas de apoio à estratégia e o modelo de planejamento estratégico utilizado. Da literatura, importante destaque deve ser dado às críticas ao planejamento estratégico por sua excessiva racionalidade e instrumentalidade (HAYES, 1993; MINTZBERG, 1994). Crítica mais recente aos instrumentos de planejamento estratégico, assim como planejamento de cenários e competências essenciais, é apresentada por Jarzabkowski e Spee (2009), que indicam que esses processos são propensos aos limites da interação entre as pessoas pela hierarquia e a distribuição das tarefas e que há pouco conhecimento sobre a forma como esses instrumentos são utilizados na prática, ou mesmo sobre suas consequências.

Dessa forma, a visão tradicional de planejamento, somada a uma abordagem sociológica, como definição constitutiva deste trabalho, assume uma perspectiva de práticas das pessoas, constituindo e buscando a prescrição das ações organizacionais, dos negócios e de seus resultados (ANDREWS, 1977; PORTER, 1980; PRAHALAD e HAMEL, 1990; BARNEY, 1991; WHITTINGTON, 1996; JOHNSON, 2007). Algumas lacunas para a adequada compreensão da adição de novas abordagens, tanto da teoria de planejamento (AGARWAL, GRASSL e PAHL, 2012) como dos estudos organizacionais, ainda não foram totalmente esclarecidas. Isso é particularmente notado quando se busca os limites entre as práticas rotinizadas dos elementos que compõem a organização e as práticas que envolvem o planejamento estratégico.

Percebe-se, pelos dados da primeira fase da pesquisa e, assim, define-se o principal pressuposto deste artigo, que a configuração tem a primazia sobre o planejamento por seus elementos, que compõem as rotinas estratégicas importantes da organização. As práticas de planejamento, por sua vez, integram os elementos da configuração organizacional.

Este artigo é consistente com a abordagem de Weick (1988), que considera a organização um composto de práticas e interações sociais; e, também, com a de Andrews (2006, p. 79-80), que argumenta que "a estratégia corporativa é um processo organizacional, de muitas formas inseparáveis da estrutura, do comportamento e da cultura da empresa onde ocorre", que a formação da estratégia desenvolve-se por um processo intelectual, com viés econômico, pela análise de risco entre a capacidade da empresa e as oportunidades de mercado, mas, ainda, por um processo que considera valores pessoais, aspirações e ideais. Este artigo também corrobora o estudo de Soda e Zaheer (2012), que tratam do exame de estruturas e processos e as interações pessoais formais e informais. Destaca-se a importância do entendimento dessas condições devido às implicações para o trabalho dos gestores e da funcionalidade das organizações. 
A seguir são apresentados os fundamentos que buscam assegurar um melhor entendimento dos dados empíricos de ambos os casos pesquisados.

\section{O planejamento estratégico}

Criar ações para o futuro visando resultados é inerente a toda função humana e organizacional. O início da década de 1950 ampliou o debate sobre a complexidade das organizações e de suas relações com o meio ambiente, dando destaque às práticas de planejamento, que serviriam para orientar as decisões que envolviam cada atividade e pessoa da organização (ANDREWS, 1977). Nessa condição, o autor inclui o tipo de negócio, os planos, as políticas e todas as demais atividades da empresa. A metodologia de planejamento que passou a prevalecer até os dias atuais é a análise conhecida como SWOT, que busca identificar os pontos fortes e fracos, as oportunidades e as ameaças (GHEMAWAT, 2002; AGARWAL, GRASSL e PAHL, 2012). Ao longo do tempo, outras abordagens foram agregadas à metodologia, como a visão baseada em recursos (WERNERFEL, 1984; BARNEY, 1991), as competências essenciais (PRAHALAD e HAMEL, 1990), a Teoria do Stakeholders (FREEMAN, 1984), entre outras.

Buscando essa integração, a literatura explora a complexa relação entre as características do ambiente, da organização, do trabalho dos participantes e do planejamento estratégico, denominando-a administração estratégica (ANSOFF e MCDONNELL, 1993); abordagem do pensamento e ação (MINTZBERG, QUINN e GHOSHAL, 2006); e abordagem das práticas estratégicas (JARZABKOWSKI, 2010; JOHNSON, LANGLEY, MELIN, et al., 2007).

Nesse sentido, em busca da ampliação da perspectiva da gestão estratégica, Mintzberg (1994) já criticava a aplicação equivocada do planejamento estratégico como técnica que reforça a ideia de que seus implementadores também devem ser os formuladores. Além disso, Mintzberg, Ahlstrand e Lampel (2007) e McNeilly (2001) alertavam para o valor das informações intangíveis, pois é necessário tempo para que as tendências, eventos e desempenhos apareçam como fatos, eles não ficam tão evidentes nos dados formais, mas, sim, nos eventos tácitos do cotidiano.

Buscando preencher essas lacunas, cresce no campo a perspectiva da estratégia centrada na ação humana ou em suas práticas, como uma atividade que se desenvolve no dia a dia, nos encontros sociais e formais, por pessoas que influenciam e são influenciadas pelo contexto organizacional e institucional; ela pode ser definida como "essencialmente uma preocupação com a estratégia como atividade nas organizações, tipicamente de interações das pessoas ao invés de estratégia como propriedade das organizações" (JOHNSON, LANGLEY, MELIN, et al., 2007, p. 3).

$\mathrm{Na}$ abordagem da estratégia como prática, o conceito de sistema de atividade "oferece uma estrutura integrada, que engloba as interações que ocorrem entre os indivíduos, o contexto cultural e histórico da sua atividade, e as diversas ferramentas e tecnologias que mediam a atividade" (JARZABKOWSKI, 2010, p. 130). Nesse sentido, os praticantes da estratégia interagem em um sistema que fornece uma base social, ou seja, esse sistema conceitua como fazer, localizado em um contexto específico, conhecido como um sistema de atividade, no qual determinados tipos de fazer podem ser mais bem compreendidos.

\section{A configuração da organização e a formação da estratégia}

A abordagem da configuração sugere que os eventos organizacionais, assim como os resultados, podem ser mais bem compreendidos quando se considera os diferentes elementos organizacionais e suas relações junto com os mecanismos integrativos que asseguram sua complementariedade (KHANDWALLA, 1977; KETCHEN, THOMAS e SNOW, 1993; MILLER, 1996). Essa premissa entende que as organizações são capazes de se alinhar com as demandas ambientais por meio dos seus atributos estratégicos, como um conjunto configuracional único desses elementos (MEYER, TSUI e HINNINGS, 1993); e, o conjunto desses 
elementos e suas características integrativas podem explicar a configuração das empresas de alto desempenho (KETCHEN THOMAS e SNOW, 1993; MILLER e FRIESEN, 1984; MILLER e TOULOUSE, 1986).

Voltando às perspectivas mais recentes sobre as atividades envolvidas no planejamento estratégico a partir das pessoas, percebe-se que a influência do perfil dos administradores e da capacidade organizacional no resultado do planejamento estratégico já havia sido identificada na proposta da abordagem da administração estratégica de Ansoff (1965). Destacam esses autores a importância dos fatores como a história passada, o tamanho, a inércia organizacional acumulada, a importância das qualificações para as necessidades ambientais e, de modo especial, as ambições, o ímpeto e as habilidades da gerência, bem como o estágio de vida das empresas e a capacidade interna. Os autores argumentam que essas características podem influenciar o desajustamento da empresa para enfrentar as mudanças de atitude propostas pelo planejamento estratégico.

Outro destaque da configuração organizacional é sugerida por Mintzberg, Quinn e Ghoshal (2006), para quem a estrutura e a estratégia existem independentemente, mas uma influencia a outra com configurações distintas: empreendedora, máquina, profissional, diversificada e inovadora. A configuração empreendedora geralmente é constituída por empresas iniciantes e agressivas, sendo que a maioria das organizações passa por essa configuração no início, de gestão centralizada e o processo tende a ser altamente intuitivo, sempre orientado para a busca de oportunidades (MINTZBERG, QUINN e GHOSHAL, 2006, p.268-274). Para o líder empreendedor, a estratégia não é um plano ou um documento formal detalhado, mas uma visão pessoal, um conceito de negócio. Nessa configuração, as decisões relativas a estratégias e operações tendem a ser centralizadas no decisor estratégico.

\section{Método}

Como visto, os casos pesquisados foram selecionadas por conta de suas especificidades, principalmente pelo rápido e constante crescimento diante dos concorrentes. Contribuíram para a escolha o levantamento de dados secundários disponíveis na mídia e o conhecimento dos pesquisadores da região na qual atuam. A escolha dos casos também se deu entre as empresas que reconhecidamente divulgam a conduta do planejamento como prática de governança ou gestão. Esses dados não são disponibilizados visando ao sigilo das empresas pesquisadas.

O passo a seguir foi receber a autorização para o desenvolvimento da pesquisa sem restrições de acesso a pessoas e a dados. As questões específicas que nortearam a pesquisa foram: a) Quais elementos constituem os principais processos organizacionais? b) Qual é o modelo de planejamento estratégico preponderante em termos de formalidade e informalidade? c) De que forma se relacionam os elementos da configuração organizacional com as práticas de planejamento estratégico?

A pesquisa foi realizada em duas etapas. A primeira procurou identificar os elementos que constituíam a configuração organizacional na forma de rotinas organizacionais mais relevantes e práticas de planejamento estratégico. As rotinas organizacionais, segundo Becker (2008), constituem a estrutura que captura as formas como a organização realiza suas tarefas em termos de padrões de comportamento e elementos claramente percebidos pelos participantes e que podem, ao mesmo tempo, ser fonte de estabilidade e mudança.

$\mathrm{Na}$ segunda etapa da pesquisa, buscou-se a existência da relação entre os elementos organizacionais configurados e as práticas de planejamento estratégico.

Nos procedimentos de coleta de dados procurou-se identificar e acompanhar as rotinas e sua interpretação pelas pessoas envolvidas, buscando identificar os significados da interação entre os indivíduos, os conceitos e, principalmente, os elementos que medeiam as atividades. Nesse sentido, buscou-se identificar para quê, onde e de que forma os praticantes da estratégia interagem ao desenvolver suas atividades. 
Como visto, a primeira fase da pesquisa possibilitou as definições constitutivas da configuração e do planejamento. A configuração pode ser definida como as rotinas organizacionais relevantes nas quais se constituem as relações que buscam alinhar os elementos organizacionais às demandas ambientais por meio dos seus atributos estratégicos. Revelaram-se como elementos relevantes em configuração: a origem da empresa, o conteúdo estratégico, a estrutura de negócios, o perfil dos gestores, a forma de gestão e o processo estratégico.

O planejamento estratégico pode ser explicado por diferentes práticas que constituem e buscam as formas de definição da estratégia, as práticas de apoio à estratégia e o modelo preponderante de planejamento estratégico. Os dados também indicam que o planejamento estratégico atua, em ambas as empresas, como um fator integrativo dos elementos da configuração organizacional.

O planejamento da pesquisa seguiu os procedimentos qualitativos para a coleta e a análise de conteúdo dos dados. Os dados secundários foram coletados por meio de documentos das empresas, sites e divulgação na mídia. A empresa de tecnologia (ET) (2010) apresenta de forma detalhada, na seção Relação com Investidores, informações como Atas das Assembleias Gerais, Atas das Reuniões dos Conselhos de Administração, Relatórios Anuais, Resultados Trimestrais, prêmios, e, inclusive, as estratégias e as vantagens competitivas. Os dados primários foram coletados mediante observação não participante e entrevistas em profundidade, no total de 7 para a rede de lojas de material de construção (MC) e 5 para a ET. A escolha das pessoas entrevistadas foi realizada por seu papel ou cargo nas organizações estudadas, conforme sua participação nas práticas estratégicas.

A perspectiva temporal da pesquisa caracteriza-se como do tipo transversal. O nível e a unidade de análise é a organização. A coleta dos dados primários foi realizada em duas etapas, a primeira entre os meses de agosto de 2010 e fevereiro de 2011 e a segunda de outubro a novembro de 2011. Realizaram-se duas reuniões com os dirigentes da MC seguidas de observação não participante das práticas envolvidas nos elementos da configuração e de planejamento. Sendo realizadas anotações de todas as etapas do processo estratégico e das características e dinâmicas das reuniões mensais da diretoria com os gerentes de loja e as reuniões diárias para discussão dos eventos relevantes do dia, descritas pelos entrevistados das lojas na MC. Foi realizada uma reunião com os dirigentes da ET. O registro dos dados foi realizado por meio de gravação, com consentimento, de todos os entrevistados.

Para efeito da análise, primeiramente foram descritos os dados secundários extraídos dos documentos, sites, relatórios e notícias da mídia. Esses dados prepararam as entrevistas da primeira fase. Após a análise dos dados da primeira fase foi realizada a segunda fase da pesquisa, com a coleta apenas de dados primários por meio de entrevistas acompanhadas de observações das práticas de planejamento e suas relações com os elementos da configuração.

Os dados primários e secundários foram abordados por meio da análise de conteúdo. A técnica utilizada foi a categorização pela classificação de elementos constitutivos do conjunto de dados, atribuindo rótulos as rotinas e elementos da configuração da organização e as práticas descritas de planejamento estratégico, de acordo com o modelo de análise (BARDIN, 2006), com as categorias analíticas teóricas estabelecidas antes e depois da coleta de dados, com a inclusão dos dados empíricos. A análise dos dados teve início com a preparação do material dos dados secundários e a transcrição dos dados das entrevistas. Nas entrevistas foram identificados os trechos relacionados a cada categoria de análise, para que fossem reveladas as evidências e a triangulação dos dados secundários e primários, ao mesmo tempo que se buscava relacionar os dados com a base teórica.

\section{A análise dos dados}

A pesquisa foi realizada em duas empresas, líderes de mercado e em forte expansão, com um longo tempo de atuação no mercado, o mesmo número de funcionários, ramos e configurações distintas. A seguir, apresenta- 
se resumidamente a interpretação dos participantes em relação aos elementos da configuração e as práticas do planejamento estratégico.

A MC caracteriza-se como uma grande empresa regional, com atuação no mercado varejista, empreendedora, de origem familiar, conteúdo estratégico estável em termos de produtos e mercados, dirigida por executivos jovens, dinâmicos e ousados, graduados e alguns com MBA, com gestão centralizada e alto grau de controle administrativo. A ET caracteriza-se como uma organização de tecnologia que atua no desenvolvimento de hardware e software para automação comercial, com filiais no país e empresas e escritórios internacionais, diversificada, de capital aberto, atuação dinâmica tanto em produtos como em mercados, de origem acadêmica, dirigida por executivos inovadores, com formação especializada, graduados com MBA e alguns com cursos e experiência internacionais, gestão centralizada, alto grau de controle e governança corporativa com políticas rígidas, articulada por executivos com experiência em empresas de grande porte.

Observa-se, principalmente, que a distinção dos elementos das configurações de ambas as organizações, caracterizadas pela origem da empresa, produtos e mercados, estrutura de negócios, perfil dos executivos, forma de gestão e práticas estratégicas, reunidos de forma sistêmica, estabelecem vínculos e caminhos distintos para as práticas de planejamento estratégico.

$\mathrm{Na} \mathrm{MC}$, os elementos da configuração organizacional e as práticas de formação da estratégia ocorrem por meio da proximidade entre as pessoas e sua interação vertical e horizontal, onde as informações fluem continuamente por comunicação oral, na qual o controle não constitui instrumento coercitivo ou limite à criatividade. Os laços familiares entre os executivos ainda são fortes e facilitam a interação entre as diferentes unidades operacionais e decisórias e trazem para a organização práticas integradas, sendo a confiança o elemento fundamental da interação e das decisões. A liderança estratégica, personalizada por seus fundadores, faz parte da conduta estratégica disseminada, evidenciada na criatividade, na busca de novas práticas e no sentimento de expansão pela conquista de novos mercados, ao mesmo tempo que se observa que o conteúdo estratégico pouco se alterou ao longo de sua história, contribuindo para uma estrutura estável, conservadora e padronizada.

Os executivos são vistos como ousados e pragmáticos, tendo aversão ao papel, à disfunção burocrática e ao formalismo; eles utilizam uma gestão que emprega pouca tecnologia, com alto grau de controle, mas privilegiam as relações interpessoais e têm proximidade com a equipe de vendas, incentivando a inovação com estruturado sistema de diálogo, recompensas e incentivos. Esse ambiente contribui para que as estratégias possam emergir da base da organização ao ápice estratégico e que, após estudo e avaliação, retornem para toda a organização como decisões estratégicas e reconhecidas como participativas (MINTZBERG, QUINN e GHOSHAL, 2006, p.130-136).

$\mathrm{Na} \mathrm{ET}$, as práticas do processo estratégico são acompanhadas por sistema de informações gerenciais, com informações que fluem das diferentes unidades para o escritório central de modo padronizado. O viés acadêmico de sua origem incutiu procedimentos de busca constante pela melhoria contínua dos processos e inovação. Como lema gerencial, a mudança constante do ambiente, de produtos e mercados indica que a empresa busca se reinventar nesse sentido. Uma governança corporativa, com conselho administrativo, conselho fiscal, comitês e diretores, além do compromisso com os acionistas, impõe um estilo de gestão formal. Com alto grau de controle, no qual as informações, análises e seus especialistas são valorizados, com utilização de indicadores de desempenho e disciplina na execução, aspectos que, de certa forma, inibem a interação informal. Para Mintzberg, Quinn e Ghoshal (2006, p.360-368) esse ambiente tende a conduzir estratégias competitivas e corporativas deliberadas, criadas no ápice estratégico por processo formal.

Dessa comparação, como apresentado na Figura 1, verificou-se que o fluxo do planejamento estratégico (setas largas) na MC caracteriza-se pela predominância do sentido de baixo para cima, mais emergente, pela aproximação com o mercado, enquanto na ET a predominância é de cima para baixo, mais formal. No entanto, percebeu-se que, em ambas as empresas, as diretrizes do ápice estratégico e as percepções da base 
da organização fluem nos dois sentidos (setas pequenas), mas com a predominância do fluxo conforme a sua configuração.

Figura 1

\section{Formação das estratégias e fluxo das práticas de planejamento}

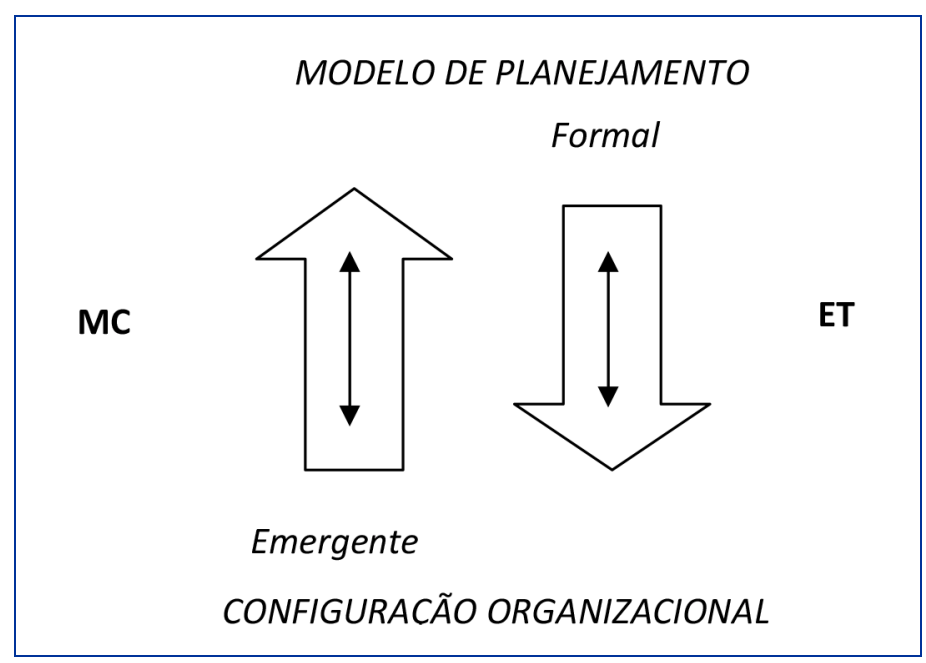

Fonte: elaborado pelos autores com base nos dados da pesquisa.

\section{Os processos organizacionais e estratégicos}

O estudo comparativo sugere forte relação entre a configuração dos elementos estratégicos com as práticas do planejamento estratégico, conforme o Quadro 1. Observou-se que nos mesmos elementos identificados em ambas as organizações foram observadas práticas com características singulares. Na MC, os processos de apoio ao planejamento foram: as reuniões, a pesquisa de mercado, o plano de chão e o controle. Com foco na ótica do processo de planejamento estratégico, esses processos representam práticas sociais que visam a detectar e disseminar continuamente informações, em geral por interação pessoal, e estabelecer vínculos com o ambiente interno e externo para capturar resultados e possíveis mudanças. Dessa forma, o processo do planejamento estratégico inicia-se nos vendedores, passando pelos supervisores e dirigentes em constante fluxo interacional.

Na ET, as práticas de apoio ao planejamento estratégico foram: as reuniões, o workshop anual, o sistema de metas, os times de resultados e o controle. Esses processos integram o planejamento estratégico visando a elaborar formalmente a visão, as metas e os objetivos estratégicos, definir os indicadores de desempenho, estabelecer os planos de ação, compilar em um único plano o planejamento estratégico, implementar e realizar seu controle, com a retroalimentação privilegiando os sistemas tecnológicos nas práticas sociais. Assim, os praticantes da estratégia concentram-se mais no ápice estratégico e, alimentados pelas informações de baixo para cima, deliberam as principais decisões estratégicas.

Pelas características evidenciadas nas organizações em estudo, as práticas preponderantes sugerem dois modelos de planejamento estratégico: emergente e formal. A MC tem como modelo preponderante o emergente, com base nas práticas sociais, sem planos escritos, sem formalidades, fazendo as estratégias emergirem da base da organização em direção à cúpula, mesmo sendo uma empresa com mais de vinte lojas. Verificou-se, nos parâmetros analisados, que a organização emprega o processo emergente devido ao dinamismo do varejo, sua estrutura com características de organicidade, a cultura familiar, a forma de gestão dos executivos focada nas práticas sociais, no mercado e nas estratégias competitivas, na forte expansão, particularmente na ampliação do espaço geográfico por meio da abertura de novas lojas, já em estudo, em 
outros estados do país. Alguns dirigentes sugerem que esse modelo poderá ser modificado, à medida que a organização se expandir e que a necessidade de coordenação e controle ultrapassar as fronteiras desse método. No entanto, também se discute a necessidade da permanência do processo do modelo atual, apoiado em práticas estratégicas e formas de gestão que privilegiem a cultura informal da organização.

A ET, por sua vez, contempla o processo formal, com base nas práticas estratégicas, a utilização de sistemas tecnológicos, o controle do planejamento pela metodologia do sistema de metas, com planos escritos, prevalecendo a criação de estratégias deliberadas pelos dirigentes. Esse processo é encontrado nas grandes corporações, estruturas mecanizadas e burocráticas, inseridas em ambiente estável e previsível no longo prazo (MINTZBERG, QUINN e GHOSHAL, 2006, p.360-368).

De acordo com as entrevistas, há a percepção da influência da academia, reduto anterior dos dirigentes, no processo formal, com a prática de cenários; a necessidade de coordenação e controle de uma organização divisionada que se expandiu rapidamente no Brasil e em três outros continentes; e o compromisso com os acionistas. Dessa forma, as estratégias são deliberadas pela cúpula no escritório central, com estratégias corporativas que buscam o crescimento e o alinhamento estratégico de toda a organização.

A pesquisa evidenciou que os mesmos elementos da configuração das empresas MC e ET conduzem a rotinas e práticas distintas. Essa argumentação foi analisada em contraprova, à medida que se questionou aos participantes da pesquisa: seria exequível a inserção de um processo formal na MC ou a utilização de processo puramente emergente para a ET?

Pelo desenho organizacional, pelos dados da pesquisa, pela opinião dos respondentes do MC e, principalmente, pela sua aproximação com o mercado, além de ter-se construído uma tradição organizacional focada nas interações pessoais e aprendizado, criando uma inércia social e uma cultura estratégica de pronta resposta, seriam encontradas muitas resistências e dificuldades de adaptação ao modelo formal, que poderia ser ineficaz, custoso, apenas cerimonial e incapaz de angariar resultados satisfatórios.

Da mesma forma, a ET encontraria enormes restrições para a utilização de um processo emergente. Sua orientação é para a melhoria contínua e a inovação apoiadas em sistemas informacionais, além de uma cultura de governança corporativa incisiva que se desenvolveu ao longo do tempo. Sendo esta considerada diretamente relacionada, pelos dirigentes, ao seu desenvolvimento, à expansão internacional e às exigências das condições de capital aberto. Esses aspectos a caracterizam como uma empresa divisionada com escritório central, o que reduz a preponderância das práticas existentes no modelo de planejamento emergente.

As práticas estratégicas da empresa MC podem ser caracterizadas por seus processos emergentes. As práticas sociais ali constituídas caracterizam-se pelo foco no cliente, pela preocupação com o funcionário e pelo bom relacionamento com os fornecedores, em uma comunicação sem restrições, informal e oral, sem formalizações de qualquer ordem. Esse ambiente faz com que as relações sejam descontraídas e propícias à criatividade e à inovação, as informações fluem de forma espontânea, sem inibições. Nesse ambiente desenvolve-se o processo de planejamento estratégico com as percepções da base da organização, de baixo para cima, deixando os padrões surgirem, emergindo as estratégias, intervindo quando apropriado, colocando, muitas vezes, a ação (execução) antes do pensamento (formulação) no processo de formalização e implementação das estratégias.

Observou-se, também, nessa empresa que existe o controle do processo e da atuação da liderança. A cúpula da empresa, o presidente e a diretoria, estabelecem as diretrizes gerais, as fronteiras e o conteúdo estratégico (produto e mercado) em um processo racional, mas alimentado por percepções que emergem da base da organização continuamente, dos "sensores" distribuídos pela rede de vinte lojas. Constatou-se que as estratégias deliberadas se limitam ao processo de expansão da empresa.

Apoiando-se no referencial teórico, as práticas ali encontradas alinham-se com a perspectiva de Johnson, Langley, Melin, et al. (2007, p. 3), que compreendem a estratégia centrada na ação humana, feita pelas 
pessoas, como uma atividade que se desenvolve nas atividades do dia a dia, nos encontros e em outros episódios, por pessoas que influenciam e são influenciadas pelo contexto organizacional e institucional, podendo ser definida como "essencialmente uma preocupação com a estratégia como atividade nas organizações, tipicamente de interações das pessoas ao invés de estratégia como a propriedade das organizações”. Essas práticas, segundo Mintzberg, Quinn e Ghoshal (2006), ajustam-se melhor ao processo emergente. Os autores destacam que essas organizações possuem "uma liderança estratégica menos preocupada com a formulação e implementação de estratégias e mais preocupadas com o processo no qual as estratégias parecem quase se formar por si mesmas" (MINTZBERG, QUINN e GHOSHAL, 2006, p. 336). Mintzberg, Quinn e Ghoshal (2006, p. 343) destaca, ainda, que o processo "é [mais bem] imaginado como formação de estratégia, pois a estratégia não é formulada conscientemente em um lugar, mas sim formada implicitamente por ações específicas executadas em muitos lugares". Mintzberg, Quinn e Ghoshal (2006, p. 346) também denomina esse processo modelo popular, por conta de as estratégias se desenvolverem a partir da base da organização.

Com os dados das práticas da ET, apesar das críticas de Mintzberg, Ahlstrand e Lampel (2007), sobre as falácias da predeterminação, do desligamento e da formalização, constatou-se que a empresa utiliza o processo de planejamento formal de forma consciente e defende que o modelo tem sido um dos fatores responsáveis pelo sucesso em seus vinte anos de existência.

O sucesso do processo formal da ET pode ser compreendido pelas práticas adaptativas à metodologia tradicional de planejamento estratégico, que, de certa forma, atenuou os efeitos das falácias apontadas por Mintzberg (1994). A origem acadêmica dos fundadores, atualmente no Conselho de Administração, e o engajamento da Seção de Desenvolvimento Corporativo no controle do planejamento estratégico, subsidiado pelo sistema de metas, é interpretado como o fator adaptativo fundamental para seu sucesso.

Quanto à falácia da predeterminação, observou-se que, embora a elaboração dos cenários envolva perspectivas para os próximos dez anos, há a renovação e atualização contínua do portfólio de produtos e serviços. A condição de empresa da área de tecnologia, na fabricação de software e hardware, impõe rapidez de respostas e flexibilidade, identificadas em consistente processo de inovação.

Constatou-se nessa empresa esforço para a divulgação do processo estratégico com o "book do planejamento estratégico", que busca demonstrar a importância do planejamento para todos os participantes da organização. Acrescenta-se a esse esforço a utilização de workshop e, principalmente, o método do sistema de metas, por meio de um sistema de informação que alimenta e retroalimenta continuamente o processo. Quanto à falácia da formalização, não se constatou na empresa evidências ou mesmo a pretensão de sua atenuação. Ao contrário, a formalização é uma das características da organização, com evidências observadas no programa de atividades, como o workshop anual, nos mapas estratégicos, no controle pelo sistema de metas e a rígida disciplina na execução do que foi planejado deliberadamente e definido no "book do planejamento estratégico". De certa forma, essas observações reforçam a validade e contemporaneidade do processo formal e se alinham com as argumentações de Ansoff e MacDonnell (1993) sobre a validade do planejamento estratégico. A seguir são apresentadas no Quadro 1 as características das práticas dos elementos da configuração organizacional e as práticas de planejamento estratégico. 
Quadro 1

Configuração organizacional e as práticas de planejamento

\begin{tabular}{|c|c|c|c|}
\hline \multicolumn{2}{|c|}{ ANÁLISE } & MC & ET \\
\hline \multirow{19}{*}{$\begin{array}{l}\text { Configuração da } \\
\text { Organização }\end{array}$} & Origem & Familiar & Acadêmica \\
\hline & $\begin{array}{l}\text { Conteúdo estratégico } \\
\text { (produtos e mercados) }\end{array}$ & Estável & Dinâmico \\
\hline & \multirow[t]{9}{*}{ Estrutura de negócios } & Grande empresa & Grande empresa \\
\hline & & 1.200 funcionários & 1.400 funcionários \\
\hline & & $\begin{array}{l}18 \text { lojas no Paraná e } 2 \\
\text { em Santa Catarina }\end{array}$ & $\begin{array}{l}9 \text { filiais, } 1 \text { fábrica e } 1 \text { universidade } \\
\text { corporativa no Brasil, } 5 \text { empresas nos } \\
\text { EUA e } 5 \text { escritórios internacionais }\end{array}$ \\
\hline & & 35 anos & 20 anos \\
\hline & & Líder de mercado & Líder de mercado \\
\hline & & Material de construção & $\begin{array}{c}\text { Tecnologia (hardware, software) e } \\
\text { automação comercial }\end{array}$ \\
\hline & & Familiar & Origem acadêmica e capital aberto \\
\hline & & Empreendedora & Diversificada \\
\hline & & Orgânica & Burocracia mecanizada \\
\hline & \multirow[t]{3}{*}{ Perfil dos executivos } & Jovens & Jovens \\
\hline & & Graduação e MBA & $\begin{array}{l}\text { Graduação, MBA e cursos } \\
\text { internacionais de gestão }\end{array}$ \\
\hline & & $\begin{array}{l}\text { Empreendedores, } \\
\text { dinâmicos, ousados, } \\
\text { mercado e varejo }\end{array}$ & $\begin{array}{l}\text { Empreendedores, dinâmicos, } \\
\text { inovadores, mercado e especialistas }\end{array}$ \\
\hline & \multirow[t]{5}{*}{ Forma de gestão } & Presidente e diretoria & $\begin{array}{c}\text { Governança corporativa, conselho de } \\
\text { administração, conselho fiscal, comitês } \\
\text { e diretores }\end{array}$ \\
\hline & & Alto grau de controle & Alto grau de controle \\
\hline & & Centralização & Centralização \\
\hline & & Comunicação oral & Comunicação por sistemas tecnológicos \\
\hline & & $\begin{array}{l}\text { Decisão intuitiva e } \\
\text { racional }\end{array}$ & Decisão racional \\
\hline
\end{tabular}




\begin{tabular}{|c|c|c|}
\hline & & Continuação do Quadro \\
\hline ANÁLISE MC & MC & ET \\
\hline \multirow[t]{4}{*}{ Definição da estratégia } & $\begin{array}{c}\text { Orientação para o } \\
\text { mercado }\end{array}$ & Melhoria contínua e inovação \\
\hline & Padronização & Personalização em massa \\
\hline & Expansão & Expansão \\
\hline & Mercado regional & Internacionalização \\
\hline \multirow[t]{5}{*}{ Práticas de apoio à estratégia } & Reuniões & Reuniões \\
\hline & Plano de chão & Workshop anual \\
\hline & Visita às filiais & Sistema de metas \\
\hline & Pesquisa de mercado & Grupos de otimização de resultados \\
\hline & Controle & Controle \\
\hline Modelo de planejamento estratégico & Processo emergente & Processo formal \\
\hline
\end{tabular}

Fonte: Elaborada pelos autores.

\section{Conclusão}

Esta pesquisa teve como motivação a descrição das relações dos elementos da configuração organizacional com as práticas de planejamento estratégico de duas organizações. As categorias de análise selecionadas para o estudo de ambas as configurações das organizações buscaram alcançar atributos relevantes da estrutura organizacional e das práticas significativas para o processo de planejamento estratégico, tendo-se em vista que a pesquisa representa apenas um recorte diante da complexidade do fenômeno e que se sugere o estudo individualizado e aprofundado de cada uma de suas categorias de análise.

Como pesquisa exploratória, as evidências descritas a seguir se referem a sugestões de debate e a recomendações para estudos futuros. É importante destacar que este artigo focou empresas com características organizacionais e práticas de planejamentos estratégicos distintos, ao mesmo tempo que alcançam sucesso e liderança de mercado quando comparadas à concorrência. Evidencia-se a análise por meio da configuração e das práticas como recurso fundamental para maior clareza das fronteiras entre as rotinas e o processo de planejamento estratégico. Isso sugere que as práticas estratégicas podem ser mais bem compreendidas quando imersas em condições organizacionais duradouras.

Em ambos os casos, identificou-se forte relação entre a configuração organizacional e o modelo de planejamento estratégico ali empregado. Os dados revelam que as características fundamentais dos elementos da configuração organizacional influenciam as práticas do processo de planejamento estratégico, constituindo processos emergente e formal distintos. Há indícios de que a configuração da organização pode influenciar as práticas de planejamento estratégico.

$\mathrm{O}$ estudo dos casos mostrou que a empresa MC define as estratégias por práticas preponderantemente emergentes. As estratégias surgem por meio de um sistema informal, baseado nas interações interpessoais e na opinião dos atores da base da organização, vendedores, clientes e fornecedores, em um fluxo de informações de baixo para cima. As informações são processadas e analisadas pelos diretores, que tomam as 
decisões estratégicas, retornando as decisões aos demais níveis da organização que, em um ciclo contínuo, novamente se retroalimenta. $\mathrm{O}$ modelo é pertinente em relação à orientação para o mercado.

$\mathrm{Na}$ outra vertente, o caso ET, diversificada, as estratégias são definidas por um processo formal. As estratégias são deliberadas pela cúpula com assessoramento técnico, alimentadas por reuniões, workshop anual e sistemas de informação e metas gerenciais. As informações são processadas e analisadas com apoio de tecnologias e práticas estratégicas instrumentais, como o sistema de metas. As decisões estratégicas ocorrem com a participação da governança, articulada pelo Conselho de Administração, pela Diretoria Executiva e pelo Conselho Fiscal, junto aos comitês de assessoramento ao Conselho de Administração, composto pelo Comitê de Estratégia, Comitê de Pessoas e Comitê de Finanças, que são difundidas e se retroalimentam por sistema de informações gerenciais. Estas colaboram com sua orientação para a melhoria contínua e inovação, enquanto a definição da estratégia é beneficiada pelo volume de informações disponibilizado e pelas práticas do modelo deliberado preponderante.

As práticas de planejamento estratégico das empresas são apoiadas por rotinas organizacionais estabelecidas em configurações distintas, com características de estrutura orgânica na MC e estrutura burocrática na ET.

Por que as duas empresas seguem caminhos diferentes? A resposta não é simples, mas multifacetada. Inúmeras justificativas poderiam ser encontradas, de acordo com a lente da teoria adotada, mas, nesta pesquisa, há indícios de que os caminhos construídos ao longo do tempo, desde a sua origem, são definidos pela estrutura organizacional e pelas formas de gestão, pelas interações sociais e pelo perfil dos executivos. Em síntese, os elementos que compõem a configuração induzem e condicionam as práticas de planejamento estratégico. Pode-se inferir, também, que o planejamento estratégico estabelecido tem alto custo de mudança, por sua dependência em relação a toda a estrutura organizacional.

Os resultados desta pesquisa também apontam indícios de que o processo emergente pode ser definido como um modelo das interações sociais, no qual as pessoas participam de forma intensa do processo. Requer ambiente participativo, aberto às críticas e sugestões de clientes, funcionários e fornecedores. Além da capacidade de a cúpula estratégica filtrar e identificar as tendências e os padrões que emergem, normalmente, da base da organização, pelo contato direto com o mercado, a fim de alimentar as decisões estratégicas.

O processo de planejamento estratégico emergente mostrou-se mais adaptado às organizações com processos organizacionais e estratégicos informais, pois, aparentemente, os sistemas formalizados inibem as pessoas a se revelarem e se exporem, sendo a comunicação oral a mais praticada pela empresa MC.

Por fim, o planejamento estratégico formalizado, embora com severas críticas, continua sendo utilizado com sucesso pela organização ET. Em uma visão mais contemporânea, são utilizadas práticas que buscam suprir deficiências do modelo com aplicações e experiências de novos modelos instrumentais, como o estudo de cenários, a visão prospectiva, o sistema de metas, os mapas estratégicos, as rotas estratégicas e os sistemas de informação em profusão.

Esta pesquisa apresenta esses achados como possíveis focos de interesse de pesquisa. Espera-se que suas limitações teóricas e metodológicas sejam vistas como estímulo a estudos futuros com os mesmos temas e sobre o mesmo campo. 


\section{Referências}

AGARWAL, R.; GRASSL, W.; PAHL, J. Meta-SWOT: introducing a new strategic planning tool. Journal of Business Strategy, v. 33, n. 2, p. 12-21, 2012.

ANDREWS, K. R. El concepto de estrategia de la empresa. Barcelona: Universidad de Navarra, 1977.

ANSOFF; I. H. Corporate strategy: an analytic approach to business policy for growth and expansion. New York: McGraw Hill, 1965.

; McDONNELL, E. J. Implantando a administração estratégica. São Paulo: Atlas, 1993.

BARDIN, L. Análise de conteúdo. Lisboa: Ed. 70, 2006.

BARNEY, J. Firm resources and sustained competitive advantage. Journal of Management, v. 17, n. 1, p. 99-120), 1991.

BECKER, M. C. Handbook of organizational routines. London: Edward Elgar, 2008.

FREEMAN, R. E. Strategic management: a stakeholder approach. Boston: Pitman, 1984.

GHEMAWAT, P. Competition and business strategy in historical perspective. Business History Review, v. 76, n. 1, p. 37-74, 2002.

HAYES, R. H. Strategic planning: foward in reverse? In: Press, 1993. p. 119-128. (Harvard Business Review Paperback). The state of strategy. Boston: Harvard University

JARZABKOWSKI, P. An activity-theory approach to strategy as practice. In: DAMON, G. et al. (Ed.). Handbook of strategy as practice. Cambridge: Cambridge University Press, 2010.

.; SPEE, A. P. Strategy tools as boundary objects. Strategic Organization, v. 7, n. 2, p. 223-232, May 2009.

JOHNSON, G.; LANGLEY, A.; MELIN, L. et al. Strategy as practice: research directions and resources. New York: Cambridge University Press, 2007.

KETCHEN JR., D. J.; THOMAS, J. B.; SNOW, C. C. Organizational configurations and performance: a comparison of theoretical approaches. Academy of Management, v. 36, 1278-1313, 1993.

KHANDWALLA, P. N. The design of organization. New York: Harcourt Brace Jovanovich, 1977.

MCNEILLY, M. Sun Tsu and the art of modern warfare. Oxford: Oxford University Press, 2001.

MEYER, A. D.; TSUI, A. S.; HININGS, C. R. Configurational to organizational analysis. Academy of Management Journal, v. 36, n. 6, p. 1175-1195, 1993.

MILLER, D. Configuration revisited. Strategic Management Journal, v. 17, p. 505-512, 1996.

.; FRIESEN, P. Organizations: a quantum view. New Jersey: Prentice-Hall, 1984.

.; TOULOUSE, J. M. Chief executive personality and corporate strategy and structure in small firms. Management Science, v. 32, n. 11, p. 1389-1409, 1986.

MINTZBERG, H. The fall and rise of strategic planning. Harvard Business Review, p. 107-114, Jan.- Feb. 1994.

; QUINN, J. B.; GHOSHAL, S. O processo da estratégia: conceitos, contextos e casos selecionados. 4. ed. Porto Alegre: Bookman, 2006.

.; AHLSTRAND, B.; LAMPEL, J. Safári de estratégia: um roteiro pela selva do planejamento estratégico. São Paulo: Artmed, 2007. 
PORTER, M. E. Competitive strategy: techniques for analyzing industries and competitors. New York: Free Press, 1980.

PRAHALAD, C. K.; HAMEL, G. The core competence of the corporation. Harvard Business Review, May-June, p. 78-90, 1990.

SODA, G.; ZAHEER, A. A network perspective on organizational architecture: performance effects of the interplay of formal and informal organization. Strategic Management Journal, v. 33, n. 6, Edição Especial, p. 751-771, 2012.

WEICK, K. Enacted sensemaking in crises situations. Journal of Management Studies, v. 25, p. 305-317, 1988.

WERNERFEL, B. A resourced-based-view of the firm. Strategy Management Journal, v. 5, n. 2, p. 171-180, 1984.

WHITTINGTON, R. Strategy as practice. Long Range Planning, v. 29, n. 5, p. 731-735, 1996. 